\title{
O USO DE IMAGENS NO ENSINO DA HISTÓRIA: UM EXEMPLO COM AS PINTURAS DE PEDRO WEINGÄRTNER
}

\author{
USE OF IMAGES ON THE TEACHING OF HISTORY: \\ AN EXAMPLE WITH THE PAINTINGS OF PETER WEINGÄRTNER
}

\author{
Cyanna Missaglia de Fochesatto ${ }^{1}$
}

\begin{abstract}
RESUMO: Este estudo pretende compreender de que forma a disciplina de História pode se utilizar de fontes visuais na sala de aula para compreensão e reflexão de eventos históricos. Para tanto, utilizou-se, das pinturas do artista gaúcho Pedro Weingärtner (1853 - 1929), que representam a temática da imigração alemã. Pretende-se analisar a identidade e representação desta etnia nas pinturas contextualizando-as com o processo histórico da época. Um dos objetivos dessa pesquisa é desenvolver as habilidades de interpretação e leitura imagética nos alunos e, igualmente incitar a discussão do uso de fontes visuais em sala de aula. Nesse sentido, a capacidade de interpretar as imagens e de relacioná-las com o contexto histórico é uma das vias para estimular o aluno no desenvolvimento da capacidade crítica, interpretativa e transformadora da sua própria realidade. Essas análises tencionam enriquecer o diálogo em sala de aula e dinamizar o ensino.
\end{abstract}

Palavras-chave: Ensino da História. Imagens. Representações.

ABSTRACT: This study aims to understand how the discipline of history can make use of visual sources in the classroom to understanding and reflection of historical events. Therefore, we used, the paintings of artist Pedro Weingärtner (1853 - 1929), which represent the theme of German immigration. Intend to analyze the identity and representation of ethnicity in the paintings contextualizing them to the history of the time. One goal of this research is to develop the skills of reading and interpreting imagery in students and also encourage the discussion of the use of visual sources in the classroom. In this sense, the ability to interpret images and relate them to the historical context is one of the ways to encourage student development of critical, interpretive and transformative capacity of your prórpia reality. These analyzes intend to enhance the dialogue in the classroom and dynamic teaching.

Keywords: Teaching of History. Images. Representations.

\section{Introdução}

\footnotetext{
${ }^{1}$ Mestranda do PPGH da UNISINOS. Bolsista Capes/Prosup
} 
O presente trabalho busca dialogar sobre o uso de imagens no ensino da Historia. Para isso utiliza-se das pinturas de Pedro Weingärtner ${ }^{2}$, de temática regional, sobre a imigração alemã, pretendendo exemplificar o uso de iconografias como fonte de estudo em sala de aula.

Essa pesquisa tensiona colaborar para desenvolver as habilidades de interpretação e leitura imagética nos alunos e, igualmente incitar a discussão do uso de fontes visuais em sala de aula. A análise desses artefatos culturais, quando utilizados na escola, pretende contribuir para o desenvolvimento de interpretação de outras fontes nos alunos, além das escritas, que são sem dúvida, mais utilizadas no ensino da História.

Outras fontes vêm tomando espaço no ensino da História, no entanto, nem professores nem alunos encontram-se devidamente preparados para fazer uma leitura mais pontual das mesmas. O exercício de análises imagéticas, de fontes orais, de documentos oficiais, como cartas, diários, e outras fontes que vão além dos textos escritos nos livros didáticos, e contribuem para uma educação mais rica. Também complementam a formação dos alunos, no sentido de estimular a fazer leituras e interpretações de diferentes fontes que vão ajudar a construir ou reconstruir o passado das sociedades, e ainda aplicar isso ao seu cotidiano, na sua própria leitura de mundo.

Atenta-se também para a importância da formação do docente, e a possibilidade de seguir sempre aprimorando seu conhecimento com cursos de extensão, especializações, palestras e demais atividades, para que assim possa dispor das ferramentas necessárias para utilização e orientação

\footnotetext{
${ }^{2}$ Foi um artista gaúcho de descendência alemã, nascido em Porto Alegre, no ano de 1853. Viveu parte da sua vida na Europa, e, ocasionalmente, vinha visitar o Brasil, para passar um tempo com a sua família. Além disso, aproveitava para expor alguns de seus quadros, principalmente no eixo Rio - São Paulo. Pintava temáticas variadas, como os temas da antiguidade clássica, imigrantes na vida rural, retratos, paisagens, festas, espaços de sociabilidade, interiores de vendas e etc. Tinha gosto pela pintura narrativa, e pela repetição de alguns elementos em seus trabalhos. Era muito cuidadoso e detalhista com suas pinturas, que sempre partiam de algum esboço prévio ou de fotografias. Foi também um dos primeiros artistas gaúchos a obter reconhecimento internacional. Morreu em Porto Alegre, no ano de 1929 (GUIDO, 1956).
} 
correta das mesmas em sala de aula. Embora isso nem sempre ocorra, por motivos variados, desde a motivação do docente, até falta de tempo ou verba para investir na sua qualificação.

Outrossim, se tornam objetivos desse trabalho, primordialmente, a análise das práticas cotidianas e culturas nas pinturas de Pedro Weingärtner, tendo como foco a identidade alemã e a forma que se pode operacionalizálas em sala de aula, especificamente no ensino da História. Para isso, a análise de duas pinturas, intituladas Kerb (1892) e Tempora Mutantur (1898) foram selecionadas.

Outro objetivo é vincular o ensino da História do Rio Grande do Sul, da transição do século XIX para $0 \quad X X$, com as pinturas analisadas, problematizando o uso de fontes visuais na educação básica. Por último, pretende-se compreender a forma que podemos aliar o ensino da História com o ensino da História da Arte, na educação básica, por meio das representações imagéticas, visando também agregar ao aluno a competência de interpretação e contextualização de imagem, discutindo essa perspectiva no ensino da História, aliando sempre o ensino com diferentes disciplinas que agreguem maior conhecimento para os alunos.

Atualmente convivemos com imagens hibridas ${ }^{3}$ que não se condicionam mais às categorias antes existentes (pintura, arquitetura, etc.), são de certa forma uma mescla de diversas áreas que se (des) encontram. Hoje é comum fazer releituras de imagens clássicas com o rompimento das fronteiras das práticas artísticas, condicionando para que também aconteça uma ampliação da utilização das fontes pra apresentar em sala de aula. Atualmente, com uso da Web $A r t^{4}$, fica muito mais fácil trabalhar imagens nas escolas e, em diferentes disciplinas, embora a prática das interpretações apresente-se em um caminho ainda a ser percorrido.

\footnotetext{
${ }^{3}$ Entende-se aqui por imagens hibridas a junção de diversas imagens resultando em uma imagem mista. São imagens características do mundo pós-modernos que misturadas se encontram ou desencontram, podendo utilizar para essa junção diversos tipos de imagens, como fotografias, pinturas, gravuras, escritos, etc. (RAHDER; CAUDURO, 2005).

4 É uma categoria de arte criada exclusivamente por meio de computadores.
} 
Dessa forma, a arte é focalizada na sua singularidade, considerando sempre o sujeito que a criou, no seu tempo e espaço histórico. No ensino da História a leitura de imagens torna-se relevante pra dar um novo, ou um outro olhar sobre esses acontecimentos históricos, sejam eles mitológicos, simbólicos ou mais corriqueiros, como as práticas cotidianas e culturais de determinadas sociedades, o modo de vida e etc. Ainda podem representar até mesmo a identidade de uma etnia, como Pedro Weingärtner retratou nas pinturas de temática regional, como na pintura Tempora Mutantur, em 1898.

Podemos dizer que a imagem vem carregada de significados, e guarda a memória de determinada época ou acontecimento. É possível explorar por meio das imagens, aspectos históricos culturais e significativos. Uma das tarefas principais da escola é estar atenta às novas visualidades, ao contexto em que elas são produzidas; é educar o aluno criticamente, alfabetizar seu olhar, para que ele não seja manipulado pelas imagens e não se torne refém dessa chamada "sociedade do espetáculo". (DEBORD, 1997).

A imagem nos oferece outros modos de pensar além do que já sabíamos oriundo das informações escritas. Isso torna a leitura de imagens significativa tanto para o aprendizado escolar quanto para a própria vida dos alunos, uma vez que enriquece o campo de análise e interpretação, e também pela riqueza da singularidade de cada olhar para o mesmo artefato. Conforme Balestrin e Soares (2012, p. 88): A imagem, como texto, pode ser lida por meio de diferentes lentes teóricas, possibilitando, dessa forma, uma multiplicidade de leituras e de análises visuais.

Este estudo situa-se na linha de pesquisa dos Estudos Culturais, sendo relevante compreender seus aspectos teóricos. Historicamente o surgimento dos Estudos Culturais e a concepção de cultura, conforme Costa (2004, p. 108):

Como tem sido já bastante discutido, os Estudos Culturais emergem num panorama mais amplo de transformação do mundo, no qual se inscrevem mudanças radicais no que diz respeito à teoria cultural. No centro dessas mudanças está a concepção de Cultura, que transmuta- 
se de um conceito impregnado de distinção, hierarquia e elitismos segregacionistas para um eixo de significados e que se abre um amplo leque de sentidos cambiantes e versáteis. Cultura deixa, gradativamente, de ser domínio exclusivo da erudição, da tradição literária e artística, de padrões estéticos elitizados, e passa a contemplar, também, o gosto das multidões.

Os Estudos Culturais buscam, antes de tudo, analisar o conjunto de produção cultural de determinada sociedade, compreender suas práticas e seus discursos para entender os padrões de comportamento. Um dos conceitos mais importantes dessa linha de pesquisa é o conceito de cultura, colocando em destaque seu significado social e político. Assim, os Estudos Culturais fazem referência às diferenças culturais, atentando para a complexidade das mesmas. Preocupa-se também com o estudo das relações de cultura, conhecimento e poder, condicionados pelo contexto social, político e econômico.

Frente a isso, este campo teórico se interessa com o contexto que está sempre em movimento, ou seja, com as mudanças e transformações culturais e políticas, com as novas formas de organização social e configurações de classe. Constituíndo o contexto como um campo fértil para explorar na linha dos Estudos Culturais e das demais disciplinas, tornando assim, a interdisciplinaridade referência para os estudos da cultura.

A educação ocorre em diferentes espaços do mundo contemporâneo, sendo a escola apenas mais um desses espaços. Estamos rodeados de artefatos culturais que constroem idéias, identidades e moldam os sujeitos. A imagem vem se tornando cada vez mais central na constituição de conhecimentos, de modos de viver, de se comportar. Nesse sentido, somos também educados por imagens, filmes, textos escritos, pela propaganda, pelas charges, pelos jornais e pela televisão, seja onde for que esses artefatos se exponham. (COSTA. 2004, p.116).

Estes novos locais de aprender e ensinar tornam-se pedagogias culturais, onde se concebe a cultura como sendo constituída por idéias, atitudes, sentimentos, linguagens, proposições morais, relações de desejo. 
[...] A cultura é assim, o solo privilegiado e bastante "problemático" no qual se realizam a educação, a pedagogia e o currículo (CORAZZA, 2001, p. 2). Essa pedagogia cultural é ancorada na diferença, e fala de um lugar onde os saberes são construídos.

Outro conceito relevante para este estudo, refere-se à identidade, conforme Costa (2004, p.115):

A questão das identidades - um dos pilares dos EC e que também tem se revelado central nos EC latino-americanos de língua espanhola emerge com mais força nos trabalhos que discutem a heterogeneidade e hibridação de algumas delas, como as de gênero, de índio, de surdos (não mais visto com um sujeito "sujeito deficiente", mas como identidade mergulhada com cultura própria), regionais (o gaúcho), de jovem, de internauta freqüentador dos chats. [...] Em tais discussões o confronto em o global e o local, entre a modernidade e a pósmodernidade, entre os discursos da tradição e os da contemporaneidade midiática assume um caráter central, num panorama ao qual a educação não se pode furtar, mesmo quando tenta mitigar a complexidade de tais processos.

A identidade ocupa um lugar importante nos estudos que tem como foco currículo e cultura, pois: Neles, analisam-se nexos entre conhecimento escolar, prática pedagógica, identidade e poder, ampliando-se o foco dos primeiros estudos críticos do currículo e da ação docente (MOREIRA, 2004. p. 125). A identidade é entendida como a forma que uni os indivíduos e os grupos. Segundo Moreira (2004, p. 126) Compartilhar uma identidade é, então, participar, com outros, de determinadas esferas da vida social nacional, religiosa, lingüística, étnica, racial, de gênero, regional, local. São esses elementos em comum que identificam os sujeitos, e a partir disso percebemos que elas não são fixas, pois podem se transformar. São plurais no sentido de abrigar todos os tipos de grupos possíveis, conforme a liquidez identitária que propõe Bauman.

Hall (2006, p. 10) falando sobre a formação do processo de identidade, afirma que: 
Assim, a identidade é realmente algo formado, ao longo do tempo, através de processos inconscientes, e não algo inato, existente na consciência do momento do nascimento. Existe sempre algo "imaginário" ou fantasiado sobre sua unidade. Ela permanece sempre incompleta, está sempre "em processo", sempre "sendo formada". [...] Assim, em vez de falar da identidade como uma coisa acabada, deveríamos falar de identificação, e vê-la como um processo em andamento.

A identidade sendo uma construção social, também permite que se pense por meio dela, nos aspectos de inclusão e exclusão. Cada grupo ou indivíduo busca conquistar seu espaço. As identidades estão sempre em mutação, e em processo de construção. Portanto, no espaço escolar é importante desenvolver a capacidade de tencionar as identidades dominantes, e a compreensão do processo de construção das identidades presentes nesse espaço. Uma vez que as identidades buscam cristalizar os valores, condutas e comportamentos.

Através desses significados produzidos podemos dar sentido às nossas experiências e aquilo que somos. A representação, compreendida como processo cultural estabelece identidades individuais e coletivas e os sistemas simbólicos nos quais ela se baseia fornecem possíveis respostas às questões (WOODWARD, 2000, p. 17). Em outra abordagem o processo de representação está vinculado aos sistemas simbólicos que dão sentindo as experiências, e, consequentemente, as desigualdades sociais.

É interessante compreender a forma que as imagens permeiam nosso cotidiano, e, inclusive, influenciam nossa vida diária. Elas são constantes em nosso mundo contemporâneo, e ajudam na constituição dos sujeitos. As imagens possibilitam uma gama muito forte de interpretações nas relações de gênero e etnia, uma vez que elas são também educadoras dos olhares e formam os discursos dos sujeitos. Elas "educam", falam e estão carregadas de significações. O leitor dessas imagens fica encarregado de interpretá-las e de buscar nelas uma identificação para participar de determinado grupo social. Pensando dessa forma, aliamos essa visão ao processo educacional, e a forma que isso é percebido nas escolas e no cotidiano dos alunos. 
O ensino da História quer produzir explicações sobre o mundo passado e atual, isso está diretamente ligado às áreas das Ciências Humanas, como a Geografia, Sociologia e Ciências Políticas. Para tanto, necessita-se dialogar com os acontecimentos diários vinculando-os às explicações dos acontecimentos passados, e a formação das sociedades, que está sempre em movimento, discutindo também as pluralidades culturais e sociais que nos permeiam.

Assim, é importante diversificar as fontes que podem ajudar a compreender esses acontecimentos do mundo. Leituras de jornais e demais periódicos, de imagens, de entrevistas, documentação diversificada, de pinturas e monumentos, também agregam ao aluno a capacidade crítica de compreensão dos aspectos históricos, sociais, culturais, políticos e econômicos.

Atualmente a visualidade que estamos submetidos nos absorve de tal maneira que é difícil imaginar a vida sem televisão, computadores, propagandas, e outros tipos de mídias e eletrônicos. Passamos por imagens a todo instante, sem - pelo menos na maioria das vezes, pararmos para analisar e compreender tais imagens, e, muito menos fazer uma críticas à elas. As representações visuais interagem com a forma em que cada ser humano vivência o mundo, guiando o olhar para interpretá-las conforme suas próprias referências de vida. Elas favorecem uma aproximação cada vez maior dos estudos das imagens com a realidade do espectador. Esse campo é interdisciplinar, pois se utiliza das diversas áreas do conhecimento e oportuniza que se pensem questões já consagradas de outra perspectiva. Chama o leitor da imagem para refletir sobre temas diferentes, seja da sociedade, ou de questões de outro cunho.

A área da pesquisa da cultura visual compreende hábitos, costumes e elementos da vida cotidiana que identificam uma cultura. É uma área que busca pensar os aspectos visuais como uma fonte de entendimento do mundo e da cultura de determinado grupo social. Para isso, a utilização de 
diversas disciplinas como Antropologia, História, Estudos Culturais, História da Arte, Sociologia, Filosofia, Geografia, devem dialogar entre si buscando ampliar o campo de conhecimento dos estudos das culturas visuais. Essa fundição de diferentes campos e disciplinas vai moldando um caráter híbrido para a cultura visual.

Possamai, (2008, p. 253) disserta sobre as questões referentes ao estudo das imagens para o historiador. Onde aponta a dificuldade que ainda existe nessa área para trabalhar com esse tipo de fontes, e na deficiência de trabalhos nesse sentido:

O estudo das imagens esteve presente em abordagens históricas desde os séculos XVIII e XIX, principalmente quando o período ou o tema investigado não poderia prescindir deste tipo de fonte, como a préhistória. [...] a utilização de imagens nos estudos históricos não é corriqueira entre os historiadores mais afeitos à tradição de trabalhar, única e exclusivamente, com os documentos escritos. Mais que predileção, a ausência das imagens nas abordagens históricas revela uma característica da formação dos historiadores que privilegiou o texto escrito, [...] De lá para cá, a situação não mudou muito.

A investigação das imagens pode abrir para o pesquisador uma gama de possibilidades a serem exploradas, principalmente no campo da memória e do imaginário. As imagens se aproximam das sensibilidades e dos sonhos e são moldadas pelas configurações de sua própria criação, sejam elas históricas ou sociais. Elas também constroem visões de mundo, crenças e utopias. São preciosas para compreender o nosso passado.

A sociedade das imagens que estamos vivendo no mundo pós-moderno ${ }^{5}$ chega até a escola, seja pelos meios de comunicação ou pelos livros didáticos, conforme Baldissera (2011, p. 252) reflete sobre essa temática:

Em tempos atuais, a maioria dos livros didáticos de História é repleta de imagens, o que reflete uma tendência atual de nossa sociedade, que é de ser dominada cada vez mais pelo visual. O apelo aos olhos chega de todos os lados: cinema, televisão, outdoors, internet, etc. Isso

\footnotetext{
${ }^{5}$ Aqui se entende o pós-moderno conforme Zygmunt Bauman (2005), que pensa a sociedade como uma sociedade líquida, onde o excesso de informações gera instabilidades, dificuldades de relacionamentos, dando formato a um novo arranjo social.
} 
modificou o contato com mundo à nossa volta, obrigando os meios de comunicação escritos - jornais e revistas - a se adaptarem às novas perspectivas, a fim de evitar que o leitor ache o texto cansativo. 0 mesmo acontece com os livros didáticos. Afinal, o público para o qual ele se destina já nasceu nessa sociedade visual por excelência.

A visualidade também tem impacto sobre a aprendizagem e desafia nosso próprio conceito de ensino-aprendizagem. Torna-se, portanto, função do professor ajudar nas leituras e decodificação desses signos que estão tão presentes em nossa vida cotidiana. O professor, então, deve igualmente, ser um alfabetizador visual. A transformação dos modos de aprender e do ensinar escolar, são reflexos do mundo em que vivemos: o mundo das tecnologias e da comunicação instantânea que permeia cada vez mais as instituições escolares.

Tem crescido o uso de fontes documentais e fontes iconográficas no ensino da História presente nos livros didáticos, ou seja, ampliam-se as fontes de conhecimentos à disposição dos estudantes, embora ainda se tenha um longo caminho pela frente no que se trata de problematizar e ensinar a refletir sobre importantes fatos históricos por variadas fontes. $O$ ensino da História, que propõe a homogeneização e que oferece perguntas e respostas prontas, está fadado ao insucesso e se afasta cada vez mais da História e do objetivo de tornar um aluno um cidadão reflexivo, crítico e capaz de transformar sua realidade. As aulas, ao contrário, devem estimular a reflexão e a interpretação das leituras, dos textos e principalmente das fontes históricas, sejam documentais ou iconográficas, ou de qualquer outra natureza.

O ensino da História tem uma função social que extrapola os limites do processo puramente educativo. Uma vez que ajuda a construir a trajetória dos sujeitos sociais, revela a memória de um passado estritamente aliado ao presente e a realidade das sociedades. Vai além de teorias e metodologias, e constitui-se como base para entendimento do mundo.

As representações cotidianas do modo de vida, contribuem para o entendimento da nossa complexa rede social, e tem como um dos seus 
objetivos apontar transformações para as realidades insatisfatórias, dotando o ensino da História de um sentido crítico para a educação como um todo. Sobre o processo de ensino da História em sala de aula, Seffner (2011, p. 213) discorre:

O objetivo de uma aula de história é a produção de saberes de natureza histórica que façam sentindo aos alunos, que sirvam para que eles se indaguem a cerca de sua vida social e familiar, de seus relacionamentos, de seus valores, de sua história enfim. Podemos dizer que o objetivo de uma aula de história é a realização de aprendizagens de conteúdos, conceitos, métodos e tradições que lhes sirvam para entender de modo mais denso o mundo em que vivem.

Dessa forma, a seleção dos conteúdos deve sempre ser feita em torno do contexto em que os alunos vivem: seu contexto social, político e cultural. A aprendizagem se torna igualmente mais significativa quando se trabalha as diversas fontes disponíveis. Além disso, deve-se valorizar cada intervenção dos alunos - seja espontânea ou não, vinculadas ou não aos conteúdos, visando dinamizar os debates e acrescentar um maior estímulo à aprendizagem e a reflexão.

O cuidado do docente que trabalha com imagens na escola também deve ser um ponto considerado. Deve-se cuidar para não complexificar demais as interpretações, dificultando o aprendizado do aluno. Outro aspecto é sempre ter o cuidado de avaliar o nível da turma, a idade dos alunos e vincular as imagens trabalhadas ao conhecimento prévio que eles têm. Uma vez que o olhar para análise de uma imagem nunca é puro. Ele sempre parte da bagagem de conhecimento que carregamos.

Ainda atenta-se que na questão da exploração da imagem, uma quinta série tem uma abstração completamente diferente de um aluno do final do ensino médio. Existe uma escala de complexidade de idades e níveis de abstrações e cognições. Isso serve também para outras atividades, e igualmente para o texto escrito (BALDISSERA, 2011, p.265).

$O$ estudo das imagens deve estar associado a análise das circunstâncias de sua criação, a vida pessoal do artista, ao contexto, etc. Ainda assim, é 
importante ressaltar a falta de cuidado de alguns livros didáticos quanto às referências das imagens, pois existe uma despreocupação em citar a referência desse tipo de fonte, o que aponta para uma desvalorização delas enquanto fonte de pesquisa e análise histórica.

Ao longo do trabalho buscou-se apontar algumas vantagens e dificuldades de vincular a imagem enquanto fonte de estudo para o ensino da História na educação básica. De forma que para pensar na intenção desta proposta, Meinerz (2011, p. 208) traz um exemplo bastante pertinente, como segue:

\begin{abstract}
Lana Maria de Castro Siman, ao investigar as leituras que alguns estudantes fazem sobre a obra "Primeira Missa no Brasil" de Victor Meirelles (1861), identifica que as representações desses" jovens tangenciam relações não só com a História ensinada, mas também com um universo cultural mais amplo vivido por eles. A pintura consagrada pela historiografia tradicional cumpre uma função importante no contexto histórico da constituição da ideia de nação no Brasil. Nas falas dos jovens, no entanto, evidencia-se a dificuldade em lidar com a obra como fonte de interpretação, pensada em sua historicidade. Destaca-se a recorrência da imagem do indígena identificado como vítima do processo colonizador, vinculada a uma vertente historiográfica importante na tradição brasileira.
\end{abstract}

Esse exemplo é muito pertinente, pois explora um pouco do que esse trabalho pretende que é usar a pintura como fonte de ensino da História percebendo a leitura que os alunos fazem ou podem vir a fazer das imagens. Colaborando para que eles desenvolvam a habilidade de trabalhar com interpretação de imagens, seja na História ou em outras disciplinas; ou ainda aplicando à sua vida cotidiana. Nesse caso, diferente do quadro da Primeira Missa do Brasil, o contexto é a imigração alemã, que tem sua relevância por tratar de uma etnia que colaborou para a formação étnico-cultural do Estado do Rio Grande do Sul.

O uso de imagens no ensino proporciona a possibilidade de questionar, de estimular a imaginação e as perguntas em torno da imagem. Isso fomenta que o aluno participe e se envolva mais com o processo de aprendizagem. Pretende-se a seguir, exemplificar o quem vem sendo 
dialogado ao longo do trabalho por meio de duas pinturas selecionadas. As pinturas são Kerb e Tempora Mutantur, ambas de temática da imigração alemã, executadas por Pedro Weingärtner. Desse modo, visa oportunizar algumas possibilidades de exemplo da forma de utilizar imagens nas escolas como fonte de ensino da História.

A representação do imigrante alemão na tela tempora mutantur , apresenta um casal trabalhando no campo. Em primeira análise podemos perceber que a imagem representa um ambiente agreste e despovoado, o que indica que esses colonos são recém-chegados e passam por um processo de estabelecimento. Nota-se pelo cenário que se tratam de trabalhadores rurais. São pessoas com o ar cansado, que abriram sulcos na terra o dia inteiro (já que o sol está se pondo). A expressão do rosto do casal remete ao cansaço ou desilusão.

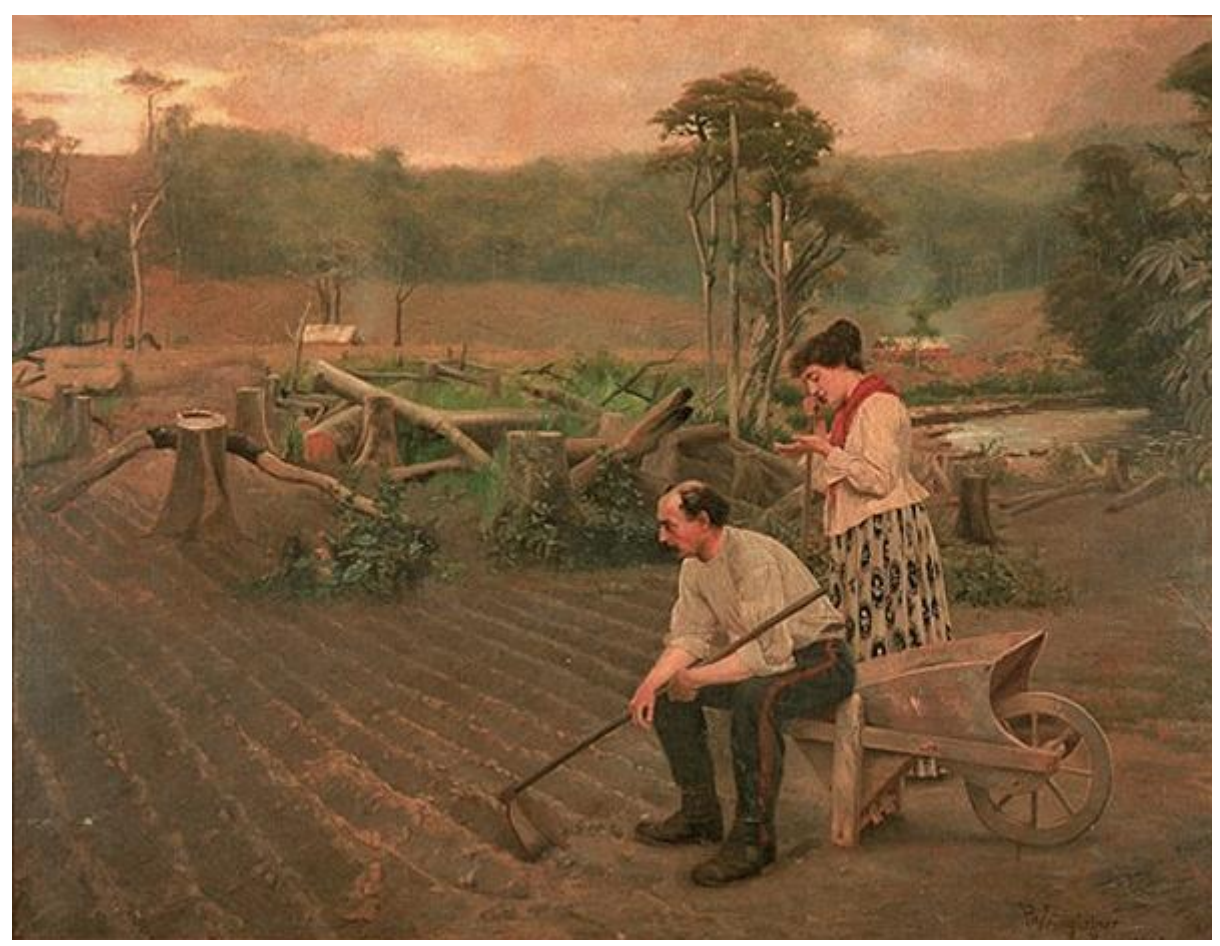

Figura 1: Tempora Mutantur, 1898.

Fonte: Museu de Arte do Rio Grande do Sul Ado Malagoli. Porto Alegre, RS.

Fundindo pintura de paisagem com pintura de gênero, a tela Tempora Mutantur apresenta alto nível de realismo, tendo sido executada no ateliê do 
artista em Roma, a partir de anotações tomadas em Santa Catarina e no Rio Grande do Sul. Pode ser interpretada também sob o ponto de vista político, social e cultural, além de propor um diálogo com outras disciplinas, como as Artes já citadas, a Geografia pelas questões de espaço e desmatamento, a Sociologia e outras mais.

Em todas essas questões o professor pode direcionar o aluno para um aprendizado sobre a imigração alemã. Onde o estimula a vincular seu conhecimento prévio à análise das imagens e a contextualização das mesmas. O que pode ser observado na tela, e que pode ser utilizado em sala de aula para complementação e enriquecimento do ensino é um aspecto para reflexão do docente.

Porque o colono foi representado dessa forma? Era assim mesmo? É assim que o livro didático explica o modo de vida dos imigrantes? Se era tão difícil porque o imigrante vinha da Europa para o Rio Grande do Sul? O que estava acontecendo na Europa para impulsionar a imigração e o que tinha aqui para o imigrante vir? Todas essas são questões que podem ser problematizadas a partir de uma breve análise dessa pintura. Essas reflexões devem ser discutidas na sala de aula, estimulando a curiosidade dos alunos para que busquem essas e outras respostas, tornando o ensino da História mais agradável, proveitoso, e mais rico para uma turma.

Frente a isso, compreende-se que essa visão que a pintura Tempora Mutantur emite sobre imigração é apenas uma forma de representação do imigrante. E que, pode ganhar outra identidade conforme outras pinturas e outros olhares, como na imagem que segue, intitulada Kerb.

As pinturas são muitos diferentes, a obra trabalhada a seguir apresenta um olhar mais positivo, e mostra um espaço de sociabilidade dos imigrantes. A representação do imigrante alemão na tela $k e r b^{6}$, na figura 2 , permite já no primeiro olhar perceber que tratar-se uma imagem muito mais positiva,

\footnotetext{
${ }^{6}$ A festa do Kerb acabou por se incorporar como atividade característica das comunidades de imigrantes alemães, tendo sido introduzida em território brasileiro pelos próprios colonos. Era uma das maiores festas da zona colonial alemã, tendo a duração de três dias. (MORAIS, 2013).
} 
pois mostra outra visão sobre o imigrante, e permite explorar outros aspectos culturais e de identidade desse grupo social.

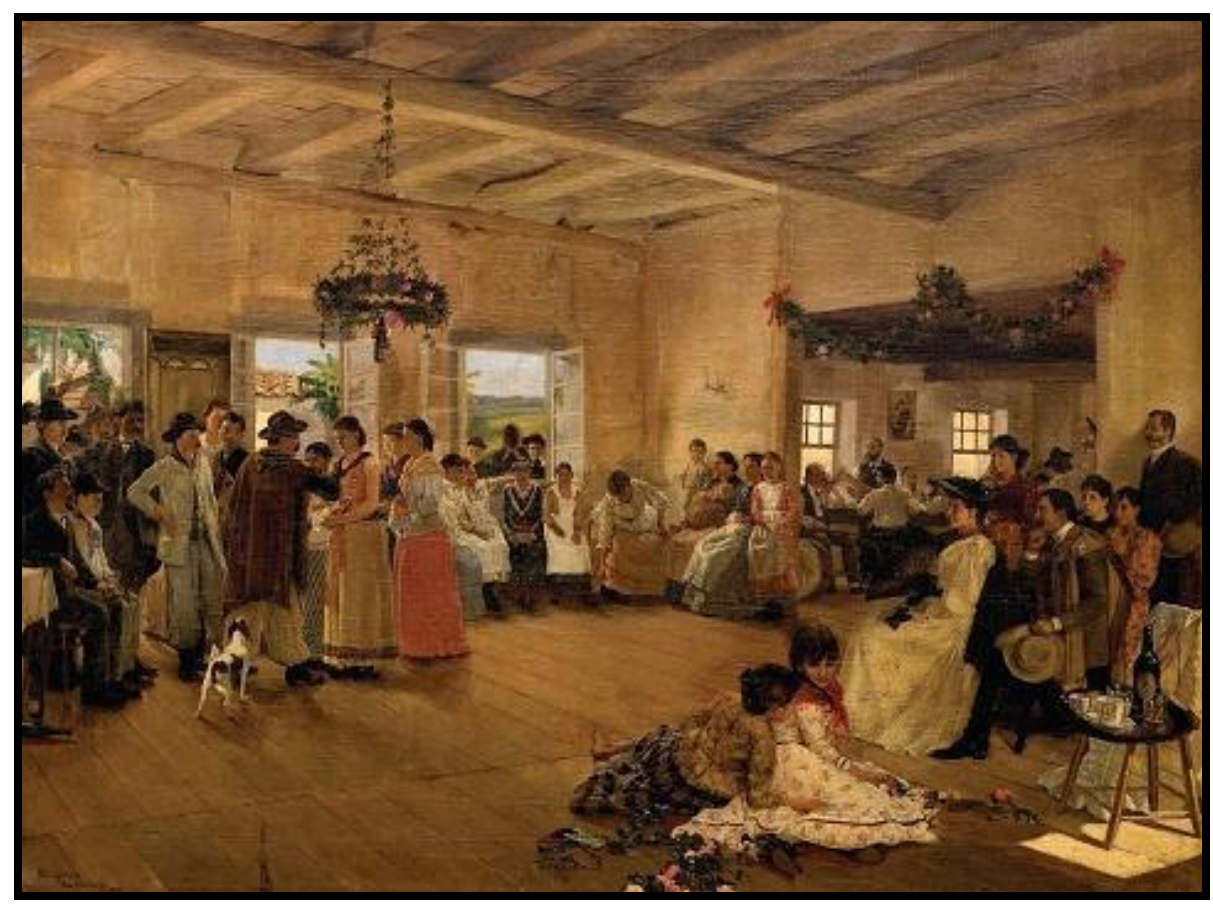

Figura 2: Kerb, 1892.

Fonte: Coleção Sergio e Hecilda Fadel. Rio de Janeiro, RJ.

Nessa imagem vemos os imigrantes em outro cenário e de outra forma. Agora aparecem bem sucedidos, bem vestidos, e num momento de lazer e descontração, diferente daquele momento pesado da imagem anterior. Percebemos que estão alegres e comemorando. Era nesse espaço que se firmavam negócios e casamentos. A alimentação, as danças, as roupas, e outros detalhes da cena vão dando contorno às questões culturais presentes nessa pintura, que podem ser vastamente exploradas numa sala de aula.

Diversos elementos podem ser observados e problematizados ao analisar essa imagem. É possível questionar aos alunos coisas sobre vestimenta, alimentação, música e questões de sociabilidade. A análise dessa imagem pode despertar discussão sobre aspectos socioculturais da imigração, e também pode vincular à questões de sociabilidade dos próprios alunos trazendo para a realidade deles, ou seja, comparando as festas de hoje com a festa do Kerb. 
Muitas são as representações culturais presentes nessa cena. Os aspectos mais simbólicos referentes à representação da imagem do imigrante alemão concernem às questões - entre outras - de status, visto que o destaque em dois momentos do quadro identifica os colonos sentados à direita. As roupas finas e a postura demonstram que são imigrantes já estabelecidos financeiramente. Representa um espaço social, onde acontece a confraternização das diversas famílias de imigrantes.

Os alunos podem ser questionados sobre quais outros aspectos eles perceberam na pintura. Além disso, se pode perguntar sobre as diferenças entre esses colonos da festa Kerb e os outros da tela analisada anteriormente (Imagem 2). Como os imigrantes ascenderam financeiramente? E socialmente? O que fizeram para isso? Que identidade podemos perceber aqui? Uma representação possível é a de imigrantes já estabelecidos e "bem de vida" no seu momento de lazer, e em um espaço de sociabilidade, onde a sua cultura emerge em cada canto da pintura. Onde podemos ver um imigrante sucedido e realizado.

\section{Considerações finais}

Como uma turma de estudantes pode ser capturada por essas imagens? O que elas podem suscitar aos alunos de um $8^{\circ}$ ou $9^{\circ}$ ano?

Inicialmente, e partindo das informações sobre a matéria que eles já possuem, podemos começar provocando-os pra que falem o que estão vendo nessa pintura da figura 1. Partindo disso, podemos iniciar questionamentos como: Em que trabalhavam e como era a divisão entre o homem e a mulher? O que plantavam e para quem plantavam? Qual era a economia? O comércio? Como eles viviam? Onde moravam?

Para depois fazer leituras mais complexas, como, por exemplo, indagar sobre o que está ausente nesta pintura, e o que poderia ser acrescentado. 
Posteriormente, pode-se estabelecer conexões com a atualidade, tendo por finalidade mostrar que a paisagem é construída historicamente. As diversas paisagens do Rio Grande do Sul foram sendo construídas a partir da ajuda desses imigrantes alemães? Esta paisagem pode ser encontrada atualmente? $\mathrm{O}$ que modificou e por quê? Perceber a forma que a turma pode responder essas questões por meio da leitura da imagem e ir colaborando para estimular a análise das mesmas trazendo os elementos visuais e os vinculando ao que foi apresentado pelo professor anteriormente e ao conhecimento que o livro didático traz. Que identidade o pintor representou ao pintar esse casal iniciando a colonização do Estado? Percebe-se prontamente que ele deu um tom pessimista para essa pintura. Nota-se a identidade de um imigrante trabalhador, que faz um serviço pesado, e que está construíndo sua moradia, plantando seu alimento. Quem está representado é o imigrante trabalhador rural, mas essa é apenas uma visão dos imigrantes que o professor pode explorar, tendo outras tantas pinturas e fotografias dessa temática.

Todos esses aspectos suscitam as mais variadas questões em sala de aula, e, frente à elas, cabe ao professor direcionar o olhar do aluno nos aspectos que não aparecem de forma tão clara nas imagens. Partindo disso, despertando a curiosidade dos alunos, poderá desenvolver com maior propriedade a capacidade interpretativa imagética deles.

Como as imagens podem ser elementos importantes para a aprendizagem de períodos históricos, são questões que esse trabalho tentou trazer para discussão. As imagens aqui apresentadas servem para elucidar uma das formas de provocar os alunos com questões referentes à análise de imagens no ensino da História. Ressaltando que existe uma gama de outras imagens que servem para esse tipo de atividade, e que visam, antes de tudo, qualificar o ensino, e desenvolver diferentes habilidades nos alunos da educação básica. 
Face ao exposto, podemos inferir algumas questões sobre o uso de imagens na educação básica. A primeira delas é referente aos benefícios que a utilização de fontes visuais pode trazer aos alunos. O alfabetismo visual perpassa a sala de aula. Muitas são as leituras de signos que podemos fazer quando criamos o hábito de vincular imagens a nossa vida cotidiana, despertando o olhar para interpretar esses símbolos que nos cercam a todo instante.

A disciplina de História traz a possibilidade de contribuir para um entendimento sobre fatos históricos ocorridos por meio de diferentes fontes, sejam documentos, literatura, imagens, fontes orais, fontes materiais, etc. Todas essas fontes somente podem ser lidas quando se tem o hábito de trabalhar com elas em aula, para que o aluno possa se familiarizar com essas fontes, a ponto de poder fazer sozinho suas próprias inferências.

Ainda tentamos trazer como exemplos de possibilidades de trabalho em aula, pinturas do artista gaúcho Pedro Weingärtner. As primeiras, Kerb e Tempora Mutantur representavam a imagem do imigrante alemão. Partindo da análise desses artefatos culturais, diversas questões sobre identidade, representação, espaços de trabalho e de sociabilidade vieram à tona e puderam ser relacionadas às questões da temática da imigração alemã no Rio Grande do Sul. Aspectos culturais, sociais, econômicos e políticos também estão representados nas pinturas, e em outras fontes visuais que servem como complemento e contribuição para o ensino da História.

Dessa forma, esse trabalho pretendeu trazer outros olhares para a discussão sobre os procedimentos metodológicos e uso de fontes em sala de aula. Visando utilizar-se de deferentes recursos, e de um diálogo entre História e outras disciplinas das Ciências Humanas, utilizando-se da interdisciplinaridade como forma de dinamizar e qualificar o ensino da História. Dando uma visão mais ampla, e possibilitando ao aluno outras formas de entendimento sobre determinados conteúdos. 


\section{Referências}

BALDISSERA, J. A. Imagem e construção do conhecimento histórico. In PADRÓS, E. S.; BERGAMASCHI, M. A.; PEREIRA, N. M.; BARROSO, Vera; GEDOZ, Sirlei. (Org.). Ensino de História: desafios contemporâneos. Porto Alegre: Evangraf, 2011.

BAUMAN, Z. Identidade. Tradução de Carlos Alberto Medeiros. Rio de Janeiro: Jorge Zahar Editor, 2005.

CORAZZA, S. M. Na diversidade cultural: uma 'docência artística'. Revista Pátio, ano V, no 17, maio/julho/2001.

COSTA, M. V. Estudos Culturais e Educação. Um panorama. In: Silveira, Rosa Maria H. (Org.). Cultura, poder e educação: Um debate sobre Estudos Culturais em Educação. 2 ed. Canoas: Ed. ULBRA, 2011.

DEBORD, G. A sociedade do espetáculo: comentários sobre a sociedade do espetáculo. Rio de Janeiro: Contraponto, 1997.

GUIDO, Â. Pedro Weingärtner. Porto Alegre: Divisão de Cultura - Diretoria de Artes da Secretaria de Educação e Cultura, 1956.

HALL, S. Identidade Cultural na pós-modernidade. 11ed. Editora: Editora: Dp\&a. 2006.

RAHDER, Maria Beatriz Furtado; CAUDURO, Flávio Vinicius Cauduro. Algumas características das imagens Contemporâneas. Revista Fronteiras - estudos midiáticos. VII. 195-205, set./dez. 2005.

MEINERZ, C. B. Ensino da História: A relação pedagógica presente em nossas práticas. 203-211. In: Enrique Serra Padrós; Maria Aparecida Bergamaschi; Nilton Mullet Pereira; Vera Barroso; Sirlei Gedoz. (Org.). Ensino de História: desafios contemporâneos. Porto Alegre: Evangraf, 2011.

MORAIS, C. de S. O Kerb. In Jangada do Brasil. Disponível em: <http://www.jangadabrasil.com.br/revista/julho80/fe80007c.asp>. Acesso em: 30 abr. 2013.

MOREIRA, A. F. B. Currículo e Estudos Culturais: tensões e desafios em torno das identidades. In: Silveira, Rosa Maria H. (Org.). Cultura, poder e educação: Um debate sobre Estudos Culturais em Educação. 2 ed. Canoas: Ed. ULBRA, 2011. 
POSSAMAI, Z. R. Fotografia, História e Vistas Urbanas História, São Paulo, n. 27, v.2, 2008. Disponível em:

http://www.redalyc.org/articulo.oa?id=221014797012. Acesso em 12 de março de 2013.

SEFFNER, F. Saberes da docência, saberes da disciplina e muitos imprevistos: atravessamentos no território do ensino de História. 213 229. In PADRÓS, E. S.; BERGAMASCHI, M. A.; PEREIRA, N. M.; BARROSO, Vera; GEDOZ, Sirlei. (Org.). Ensino de História: desafios contemporâneos. Porto Alegre: Evangraf, 2011.

SEFFNER, F. T. metodologia e ensino de História. In GUAZZELLI, C. A. B; PETERSEN, S. R. F.; SCHMIDT, B. B.; XAVIER, R. C. L. (Org.). Questões de Teoria e Metodologia da História. Porto Alegre: Editora da Universidade, 2000.

WOODWARD, K. Identidade e diferença: uma introdução teórica e conceitual. In SILVA, T. T. da. (Org.). Identidade e diferença: A perspectiva dos estudos culturais. RJ: ed. Vozes, 2000.

Recebido em 06 de setembro de 2013.

Aprovado em 23 de dezembro de 2013. 